\title{
OS CAMINHOS INCERTOS E OS ENTRAVES NA CONSOLIDAÇÃO DA IDENTIDADE DO COORDENADOR PEDAGÓGICO
}

\author{
THE UNCERTAIN ROADS AND THE ENTRAVES IN THE CONSOLIDATION OF THE \\ IDENTITY OF THE PEDAGOGICAL COORDINATOR
}

\author{
Elizângela das Chagas Lemos \\ Raquel Cássia Domingues Morato
}

\begin{abstract}
RESUMO: Este trabalho teve como tema os caminhos incertos e os entraves na consolidação da identidade do coordenador pedagógico, objetivando identificar os entraves e as incertezas no processo de reconhecimento da identidade do coordenador. As diligências acerca deste tema surgiam ao perceber que a identidade desse profissional é, constantemente, limitada no âmbito escolar. Em muitos casos, percebe-se que o coordenador pedagógico é o centro de críticas no contexto escolar diante do processo atribulados, ou seja, sempre age de forma urgente do que ser/fazer pedagógico que perpassa nas indecisões das suas reais colaborações. Como ponto de reflexão, partimos da conjectura sobre a construção da identidade profissional do coordenador pedagógico. Com este objetivo, o primeiro item analisa os entraves no reconhecimento da identidade profissional. $O$ segundo apresenta a pesquisa sobre os desafios de um profissional em construção. $O$ terceiro apresenta a prática pedagógica na atuação do coordenador. Para o desenvolvimento deste ensaio optou-se por uma abordagem qualitativa de caráter exploratório, cujo autores referendaram significativamente, e os entraves e incertezas sobre a consolidação da identidade profissional, os desafios e as práticas do coordenador pedagógico.
\end{abstract}

Palavras-chave: Entraves. Identidade profissional. Coordenador pedagógico.

ABSTRACT: This work had as its theme the uncertain paths and obstacles in the consolidation of the identity of the pedagogical coordinator, aiming to identify the obstacles and the uncertainties in the process of recognition of the coordinator 's identity. The diligences on this theme arose when realizing that the identity of this professional is, constantly, limited in the scholastic scope. In many cases, it is perceived that the pedagogical coordinator is the center of criticism in the school context before the process, that is, it always acts in an urgent way than being / doing pedagogical that runs through the indecisions of their real collaborations. As a point of reflection, we start from the conjecture about the construction of the professional identity of the pedagogical coordinator. With this aim, the first item analyzes the obstacles in the recognition of the professional identity. The second presents the research on the challenges of a professional under construction. The third presents the pedagogical practice in the work of the coordinator. For the development of this essay we opted for a qualitative approach of exploratory nature, whose authors endorsed significantly, and the obstacles and uncertainties about the consolidation of professional identity, challenges and practices of the pedagogical coordinator.

Keywords: Inside. Professional identity. Pedagogical coordinator. 


\section{INTRODUÇÃO}

Este artigo vem abordar sobre os entraves e as incertezas sobre a consolidação no processo do reconhecimento da identidade profissional do coordenador pedagógico, os seus desafios na construção do profissional e as práticas pedagógicas na sua atuação. Sabemos que o coordenador pedagógico está em fase de conquista do seu espaço e são inúmeras as discussões em torno da sua atuação, dos seus desafios e das suas atribuições enfrentadas diariamente. Mediante a isso, vivemos em uma sociedade que a escola enquanto instituição de ensino e de práticas pedagógicas enfrenta diversos desafios que afetam a sua ação frente às problemáticas no contexto escolar, demostrando uma necessidade por parte do coordenador pedagógico uma maior conscientização sobre o seu papel e uma formação qualificada adequada para esse profissional.

Assim, o interesse pelo tema de pesquisa aqui apresentada surgiu de leituras e inquietações feitas durante o processo de construção da dissertação do mestrado, percebemos que, o coordenador enfrenta dificuldades em consolidar e assumir a identidade profissional. Diante destas indagações, a profissão do coordenador pedagógico abrange singularidades que a diferencia dos demais profissionais, ou seja, não é suficiente apenas carregar um título acadêmico, é preciso

dedicação, está disponível quando há necessidade, buscar exercer sua prática com ousadia alcançando os limites de sua função.

Sobretudo, neste trabalho uma das atribuições do coordenador pedagógico é entendida como ação que se manifesta no esclarecimento reflexivo e transformador da práxis docente. Assim, esse trabalho é desenvolvido por profissionais que deve estar voltado a compreensão, organização, para fins coletivamente e transformação da práxis docentes.

Sabemos que a educação contribui no contexto social e no profissional, assumindo as responsabilidade e papéis, que vão além da transmissão e construção de conhecimento teórico e prático, inteirando uma responsabilidade maior na construção e no desenvolvimento de identidades, passando por diferentes níveis de educação, além do desenvolvimento de uma consciência crítica e emancipatória do profissional.

Segundo Oliveira (20II apud Dubar 1997, p. II7), o processo de socialização permite compreender a noção de identidade numa perspectiva sociológica restituída numa relação de identidade para si e identidade para o outro.

A identidade deve ser entendida como uma categoria coletiva, além disso, ela corresponde aos seus valores, crenças, desejo, arbítrio. A identidade profissional é um processo de construção 
que reflete o contexto e momentos históricos respondendo, dessa forma, às novas questões restritas pela sociedade. É relevante ressaltar que essa identidade é colocada em prática através da carreira, que por sua vez é construída por ações e escolhas que permitem uma constante evolução profissional.

A busca pela a identidade profissional do coordenador pedagógico nas instituições formais de ensino, nos possibilitou a descoberta de que esse profissional ora e visto como supervisor educacional, ora visto como orientador ou visto como inspetor. Mediante a tantos papéis, o coordenador pedagógico agirá como ator social, agente facilitador e problematizador da ação docente, primando pelas intervenções e norteamento mais exequível ao processo ensino e aprendizagem.

O coordenador pedagógico é peça fundamental dentro da escola, pois, este deve buscar integração dos envolvidos no processo ensino e aprendizagem mantendo relação interpessoal de maneira saudável valorizando a sua formação e a do professor desenvolvendo habilidades para lidar com as diferenças com objetivos de ajudar efetivamente na construção de um espaço que favoreça um ambiente de qualidade. (DAVID,p.148. 2017).

Sabemos que o coordenador é uma peça fundamental no contexto escolar e deve subsidiar e organizar a reflexão dos professores sobre as razões que abonam suas escolhas pedagógicas e sobre as dificuldades que encontram para desenvolver sua função, o coordenador está beneficiando a tomada de consciência dos professores sobre suas ações e o conhecimento sobre o contexto escolar que atuam.

Outro ponto a ser discutido, é a dificuldade encontrada e a definição de um território próprio para o trabalho pedagógico, a falta de uma identidade clara para a função, acaba agravando o isolamento desse agente escolar em relação aos colegas que realizam o mesmo trabalho em outras unidades escolares. Outra dificuldade seria a atuação consciente nas atribuições para conduzir, organizar e defender projetos no contexto escolar.

É notório que, os docentes enxergam o coordenador pedagógico como um rival no processo de ensino e aprendizagem, (principalmente professor de disciplinas), para eles o coordenador é uma figura que fiscalizar, impõe, desconstrói as ações pedagógicas programadas por eles, (em muitos casos, eles não aceitam sugestões para o avanço do processo de ensino e aprendizagem).

A relevância em desenvolver esse tema, justifica -se em analisar os entraves no reconhecimento da identidade profissional para a função do coordenador pedagógico, os seus 
principais desafios profissionais em construção realidades vivenciadas no contexto escolar e a prática pedagógica na atuação do coordenador. Portanto, ressaltamos que a escolha por esta temática é em virtude de algumas reflexões e vivencias sobre a prática do coordenador pedagógico, de suas inquietações e inconformidades com algumas situações do cotidiano escolar. Infelizmente, o cotidiano do coordenador pedagógico está distante do ideal preconizado pelos diversos autores.

Nessa esfera, procuramos entender os entraves, desafios e a prática do coordenador, já que as dificuldades apontadas são componentes decisivos para fragilizar a consolidação da identidade dos coordenadores pedagógicos.

Em suma, em meio toda a instabilidade no reconhecimento da identidade profissional, o coordenador encontra-se muitas vezes forçado no exercício de sua atribuição, na qual em prática não possui uma forma de papel definida. Mediante a estes aspectos, esse agente escolar deve ter algumas características que desfavorecem o seu desempenho profissional.

\section{REVISÃO BIBLIOGRÁFICA}

A revisão bibliográfica para esta pesquisa será constituída, inicialmente, por autores que

analisam e entendem os entraves no reconhecimento da identidade profissional para a função do coordenador pedagógico, os seus principais desafios profissionais em construção realidades vivenciadas no contexto escolar e a prática pedagógica na atuação do coordenador.

Nessa perspectiva, a contribuição de autores como Souza (2013), Gomes (2-13), Lima (2012), Santos (2012), Silva (2012), Souza (2013), Araújo e Silva (2012), dentre outros, com os quais trabalhamos, foram imprescindíveis para conhecer e entender melhor o processo de consolidação, entraves da identidade do coordenador pedagógico, os seus principais desafios e a sua pratica pedagógica.

Souza (2013), Gomes (2013), enaltece que a identidade deve ser coletiva, ou seja, algo só identificável em relação a outro que tenha caraterísticas semelhantes.

Lima (2012), Santos (2012), Silva (2012), irão contribuir através do olhar histórico sobre o desvio de função do coordenador pedagógico ou se houve realmente, uma função específica deste agente pedagógico.

Souza (2013), sinaliza sobre o fascínio de desvendar como é tecida a identidade profissional do coordenador pedagógico nos espaços escolares. 
Araújo e Silva (2012), por sua vez, conceitua a real identidade do coordenador pedagógico no espaço escolar e apresenta os desafios que comprometem a sua ação frente as problemáticas que surgem no espaço escolar.

Em suma, os conceitos e seus respectivos autores concretizam significativas contribuições para os objetivos que se espera alcançar com esta pesquisa.

\section{METODOLOGIA}

O debuxo metodológico escolhido para as devidas justaposições do presente artigo será analisar os entraves no reconhecimento da identidade profissional, os desafios e a prática pedagógica, investigação que congregue o uso de técnicas qualitativas que serão realizadas nas escolas municipais da microrregião litoral Sul, no Município de Arês e Goianinha. No estudo a ser realizado, quanto à abordagem do problema, de cunho qualitativo foi definido por considerar que há uma relação dinâmica entre o mundo objetivo e concreto.

Pode-se definir método como caminho para se chegar a determinado fim. E método científico como o conjunto de procedimentos intelectuais e técnicos adotados para se atingir o conhecimento. (GIL, 2008 p. 28).

A pesquisa de acordo com os objetivos determinados será descritiva-exploratória, optouse também como um dos instrumentos e procedimentos a serem utilizados no campo da presente pesquisa, a realização de questionário com os coordenadores e gestores.

A entrevista foi de caráter semiaberto, desenvolvido com base em um roteiro básico, previamente elaborado, com perguntas abertas e fechadas, para a construção dos dados de análise. E será exploratória, pois busca levantar e definir mais informações sobre o assunto, para delimitar o tema de pesquisa, definir objetivos, levantar hipóteses e é claro fazer descobertas sobre o assunto em questão. Dessa forma, os conceitos e seus respectivos autores trazem efetiva contribuição para os objetivos que se espera alcançar com esta pesquisa.

\section{RESULTADOS E DISCUSSÕES}

Este estudo se baseia na premissa dos entraves e as incertezas sobre a consolidação no processo do reconhecimento da identidade profissional do coordenador pedagógico, os seus desafios na construção do profissional e as práticas pedagógicas na sua atuação. 
Em relação ao primeiro objetivo, percebe-se que a identidade do coordenador pedagógico é, muitas vezes, pouco definida no contexto escolar e que pode ser consolidada e fortalecida a partir da conscientização e a real função do papel do coordenador pedagógico no âmbito escolar.

Desta forma, partimos do pressuposto de que a identidade profissional é construída diariamente nas atividades que abrangem o coletivo.

Discutir a identidade do coordenador pedagógico pode significar rever posições, resgatar experiencias, retomar conflitos, fazer novas reflexões, fazer opções, entrar em embates, enfrentar diferenças e se adaptar as novas mudanças. No Brasil, o coordenador pedagógico não tem uma identidade definida tanto por aquele que exercer a profissão quanto à legislação que legitima, tonando um grande problema que vem se configurando nas instituições educacionais. Assim, vale ressaltar que a identidade profissional do coordenador está estruturada nas experiências de vida, nas relações interpessoais e nos elementos que compõem a sociedade e a modernidade.

Para gestora A, a identidade profissional precisa ser definida e ser conquistada, pois o coordenador não consegue exercer corretamente a sua real função nas atividades do contexto escolar.

[...] eu acho que a gente tem muito ainda pra conquistar falando como coordenadora pedagógica, porque a coordenação pedagógica é, já tive experiencia de coordenação pedagógica e a gente termina e não consegue fazer o nosso trabalho, porque o coordenador pedagógico, ele é visto na escola como um... vamos colocar assim, popularmente, conhecido como faz tudo, né! Tudo, ah! Pede pro coordenador pedagógico fazer, né! ah, faltou um professor, pede por coordenador pedagógico, pede pra ele ficar na sala de aula. Aí a gente fica muito atrelado as questões administrativas, né! Porque de certa forma não deixa administrativas e o pedagógico o que realmente a gente tem que tá voltado pra fazer o tempo fica bem curtinho. Então eu acho que a questão da identidade do coordenador pedagógico tem muito que conquistar ainda nos que diz respeito realmente a competência do coordenador pedagógico, ao que cabe ao coordenador pedagógico. Porque eu vejo que durante esse período ainda não sei se é só por parte da ou até mesmo por parte do coordenador.

A busca pela a identidade ainda falta muito a se conquistar, devida o excesso de atribuições da coordenação. Esse excesso acaba provocando equívocos na compreensão do papel do coordenador pedagógico perante as atividades institucionais. Ou seja, no contexto escolar, os desafios ou entraves entre a formação continuada de docentes e as urgências escolares, é necessário analisá-las para não tornarem insignificante no processo da busca pela a identidade profissional.

O segundo objetivo explorado foi investigar os desafios de um profissional em construção. Toda a escola precisa de um líder, esse líder é uns dos papéis desempenhados pela 
coordenação pedagógica, ou seja, o coordenador é aquele profissional que visualiza o futuro das atividades escolares, como por exemplo: as reuniões pedagógicas, reuniões de pais e mestres, aplicação dos projetos, as avaliações institucionais e as metas a serem alcançadas no trabalho pedagógica da instituição. Para a Gestora, os desafios enfrentados são diferentes devidos aos seus segmentos. Vejamos o seguinte relato:

[...] são realidades diferente, no horário da manhã, por exemplo! O desafio maior e você conseguir sentar realmente com aqueles professores pra planejar, né! A rotina mesmo do planejamento. Por que? Porque como aqui o universo e grande até o horário pra gente fecha um horário, pra gente fecha o dia do planejamento por disciplina muitas vezes a gente não consegue, porque o professor ele tá aqui e tem uma carga horário complementar em outra escola, então essa, eu acho que a maior dificuldade e achar um "interrupção" e acha esse tempo pra realmente sentar e planejar da forma que devia ser por conta da necessidade de juntar por disciplina por área, né!

Cabe a coordenação perceber as dificuldades, angústias e necessidades dos educadores e educandos, buscando gerenciar esses conflitos dentro da unidade escolar. A função do planejamento é resolver, transformar à prática e tornando-a com menos sofrimento. Nesse sentindo, a coordenação acaba desviando de sua função em detrimento de outras necessidades peculiares, o papel dela é ininterrupto, na rotina de trabalho, resultando a redução do tempo destinado às atividades inerentes ao seu cargo, cujo a essência é coordenar o processo de ensino e aprendizagem dos alunos. Ela deve pensar uma estratégia conjunta, buscando o comprometimento com todos da comunidade escolar de forma substancial.

O coordenador é um profissional que responde pela socialização, integração, viabilização e articulação do trabalho pedagógico, sendo diretamente correlacionados com inúmeras relações, as quais deve ir de encontro aos aspectos de colaboração. Para as gestoras A e B, os desafios enfrentados pelo coordenador pedagógico pontuados das seguintes maneiras:

O principal desafio, eu acredito que são mais com os professores mais antigos, são bem enjoados, né! É aquela residência! A residência que o professor antigo tem de sentar-se com o coordenador, pro coordenador ver como tá o planejamento dele, né! Como tá a aula dele. Então, eu acho que é isso. É o maior desafio que a gente enfrenta aqui. (gestora $\mathrm{A}$ ).

Desafios são muitos. Desafio é, às vezes juntamente com o próprio professor, [...] A opinião é a principal ponto, a ideia, as ações, sua habilidade de um coordenador de repassar para o grupo. [...] (gestora B).

É evidente que o maior desafio enfrentado está relacionado ao saber lidar com professores, principalmente aqueles em final de carreira, os que já conquistaram seu espaço, os mais resistentes às mudanças na cultura escolar, por acharem que da forma como está de ficar. Em 
muitos casos, quando se trata de determinado profissional, nem sempre a relação estabelecida com ele e mais experiente e acolhedora.

O terceiro objetivo, a atuação na prática pedagógica do coordenador, é necessário ressaltar que, essa prática não só se restringe à padrões burocráticos, ela deve buscar estabelecer, acima de tudo, reflexão sobre a sua atuação como a articulador, e mediador do P.P.P. da instituição, a formação continuada dos docentes e por último, a construção e acompanhamento do planejamento.

A prática pedagógica enfrenta descanso diante das reais funções do coordenador é constante na sua rotina resolver demandas de urgência, agindo de forma imediatista, produzir atividades, tirar a xerox, resolver problemas na secretaria sobre o discente, ficar na portaria, se afastando as sua real atribuição, que é o articulador, mediador e a formação dos professores. Ele deve estar inserido na educação para propor uma formação de aperfeiçoamento, estimulando, transformando e buscando uma autorreflexão sobre a prática pedagógica em prol da qualidade de ensino e aprendizagem.

Em síntese, procurou-se neste artigo avaliar o processo de consolidação da identidade profissional do coordenador pedagógico, é importante apontar que as formas identitárias assumidas pelo profissional não são permanentes ou estanques, mas se transformam, em movimento dialético constante, em um jogo de forças em que as características da pessoa, sua história, suas habilidades e competências profissionais, segundo pressupostos de Pacco e Souza.

\section{CONCLUSÃO}

Buscando refletir sobre os conhecimentos através dos estudos e observações, que a prática pedagógica requer que se faça uma educação voltadas para toda a coletividade, de modo que todos os envolvidos possa usufruir dos mesmos benefícios, deveres e direitos, mesmo que essa ação configure-se em diferentes espaços sociais, mas mantenha sua atribuição transformadora para o ensino de qualidade. Acreditamos que o coordenador identifique parcialmente seu papel dentro do âmbito escolar, compartilhe seus conhecimentos, suas ideias, conheça sua equipe, seu espaço de trabalho, tornando-se desde modo à ligação fundamental para o desenvolvimento da prática educativa, buscando assim o seu caminho mediador, transformador, articulador e formador.

Em vista disso, o ato de coordenar acaba exigindo diferentes conhecimentos, competências e habilidades gerais e especificas, do coordenador pedagógico na sua atuação. 
Enquanto esse agente escolar não tiver consciências plena do seu papel, ele acaba enfrentando dificuldade para definir um território próprio para a sua atuação, acarretando a falta de uma identidade sólida, evitando assim, o isolamento da categoria dos coordenadores pedagógicos, o desfio de função e cargas exaustivas.

Em suma, o coordenador é um profissional que geralmente atua nas soluções de problemas, seja ela, no conflito de necessidades ou interesses, seja na esfera pedagógica, administrativa ou burocrática. Esse profissional precisa ser paciente, agiu, persistente, perspicaz, criativo, inovador, incentivador e mediador de conflitos. Mediante a esse cenário, esse agente escolar acaba assumindo diversas facetas impostas pelas necessidades iminentes da sua função. Ele deve buscar a mudança de hábito, só assim ele passa a conhecer e conscientizar o seu papel, agindo de forma diferente e buscando novos comportamentos dentro do contexto escolar.

\section{REFERÊNCIAS BIBLIOGRÁFICAS}

ARAúJO, Andreza Cristina Santos e SILVA, Tiago Pereira. A Real Identidade do Coordenador Pedagógico no Espaço Escolar. [Blog de internet]. Consultado em 29/o5/2019.

DAVID, Ricardo Santos. A construção da identidade do coordenador pedagógico e seu perfil profissional no contexto atual. 2017.

Disponível

〈http://www.periodicos.ufc.br/labor/article/view/r8o2>. Acesso em: 27 set. 2018.

Disponível: http://pedagogiaclamada.blogspot.com/2012/II/sumario-I.html

FRANÇA, Luísa. Entenda os maiores desafios do coordenador pedagógico. Disponível em: https://www.somospar.com.br/coordenador-pedagogico-desafios/ Acessado em 12/12/2018

FRANCO. Maria Amélia Santoro. Coordenação pedagógica: uma práxis em busca da sua identidade. Revista Múltiplas Leituras, VI, n.I p. I37-I3I, jan. 2008.

LIMA, Maria Angélica Pedrosa de; SANTOS, Diego Gomes do; SILVA, Thamine Araújo. O coordenador pedagógico na educação básica: Desafios e perspectivas. Revista Labor, Pernambuco, v. I7, n. oI, p.oI-I2, I3 set. 2012. Disponível em: 〈http://www.periodicos.ufc.br/labor/article/view/ı88oz >. Acesso em: I8 dez. 2018.

LIMA, P.G.; SANTOS, S, M. O coordenador Pedagógico na Educação Básica: Desafios e Perspectivas. Educare et Educare. São Paulo: p 77-90, jul/dez. 2007.

OLIVEIRA, Patrícia Webber Souza de. Construção de identidades profissionais: da formação profissional à vivência da inserção no mercado de trabalho. Revista Labor, [S.1.], v. I, n. 6, p. II5- 
133,

mar.

2017.

ISSN

1983-500o.

Disponível

em:

$\langle$ http://www.periodicos.ufc.br/labor/article/view/9306〉. Acesso em: 3I mar. 2019. doi:http://dx.doi.org/ro.29148/labor.vii6.9306.

PLACCO, Vera Maria N. de Souza e SOUZA, Vera Lucia Trevisan de. Desafios ao coordenador pedagógico no trabalho coletivo da escola: intervenção ou prevenção? IN: PLACCO, Vera Maria N. de Souza e ALMEIDA, Laurinda Ramalho de (Org.). O coordenador pedagógico e os desafios da educação. São Paulo: Edição Loyola, Io ed. 2008, 2 ed. 2010. P. 25-36 RAMOS, Illa de Souza. A identidade profissional do coordenador pedagógico: Caminhos incertos. Educere: XI congresso nacional de educação, Curitiba, v. o, n. o, p.13093-I310I, 23 set. 2013.

RIBEIRO, Raimunda Maria da Cunha. O coordenador pedagógico na escola públicas, dilemas, contradições e desafios de um profissional iniciante. Revista Reflexão e Ação: revista reflexão e ação, Santa Cruz do Sul, v. 24, p.59-78, maio 2016. Disponível em: 〈https://online.unisc.br/seer/index.php/reflex/article/view/5718〉. Acesso em: 03 nov. 2018. 